\title{
TREN PENGEMBANGAN MEDIA DALAM BIMBINGAN KARIER SMP: ULASAN PENELITIAN DI INDONESIA PADA TAHUN 2012 - 2018
}

\author{
Betty Nurbaeti Rachman ${ }^{1)}$ \\ 1) Universitas Negeri Jakarta, DKI Jakarta, Indonesia \\ E-mail: ibunurbaeti@yahoo.com
}

\begin{abstract}
Abstrak. Beragam penelitian pengembangan (R\&D) media bimbingan karier ini telah dilakukan sejak 2012-2018 oleh mahasiswa prodi bimbingan dan konseling di Indonesia. Penelitian ini mengulas tren media bimbingan karier pada jenjang SMP dan memberi evaluasi agar penelitian pengembangan media berikutnya dapat lebih inovatif dan efektif. Terdapat 27 penelitian pengembangan media bimbingan karier selama 2012-2018. Secara kuantitas, tren pengembangan media mengalami peningkatan. Adapun jenis media yang paling banyak dikembangkan yakni media yang terintegrasi komputer/internet. Namun, penelitian pengembangan media yang telah dilakukan belum membahas aspek kompetensi karier siswa SMP. Peneliti menyarankan agar penelitian selanjutnya mengacu pada ASCA Standard atau NOICC Middle School Competencies.
\end{abstract}

Kata Kunci: Tren Media; Bimbingan Karier SMP; Analisis Konten

\section{Pendahuluan}

Layanan bimbingan dan konseling memiliki peran dalam membantu peserta didik menyelesaikan tugas-tugas perkembangannya. Untuk itulah layanan bimbingan konseling harus berahir pada pencaapaian tugas perkembangan. Ada 4 aspek tugas perkembangan yaitu: 1) aspek pribadi, 2) aspek sosial, 3) aspek belajar dan 4) aspek karier. Berarti salah satu tugas perkembangan peserta didik SMP/MTs adalah aspek karier.

Siswa Sekolah Menengah Pertama (SMP) termasuk individu yang memiliki rentang usia 15-18 tahun. Dengan rentang usia tersebut siswa termasuk dalam tahap perkembangan remaja. Perkembangan remaja merupakan masa periode yang dijalani seseorang sejak berakhirnya masa kanak-kanak sampai datangnya awal dewasa. Remaja memiliki tugas perkembangan yang mengarah kepada kesiapannya memenuhi tuntutan dan peran sebagai orang dewasa yaitu merencanakan masa depan.

Savickas [1] menyatakan bahwa remaja mulai mengungkapkan masa depan mereka dengan sungguhsungguh. Remaja mulai memberikan perhatian yang besar terhadap berbagai lapangan kehidupan yang akan dijalaninya sebagai manusia dewasa di masa mendatang.

Mengacu pada Standar Kompetensi Kemandirian Peserta Didik (SKKPD) SMP, tugas perkembangan karier siswa meliputi: 1) perilaku kewirausahaan (kemandirian perilaku ekonomi), dan 2) wawasan dan kesiapan karier.
Dalam memenuhi tugas perkembangan karier siswa, guru BK memberikan beragam layanan mulai dari layanan informasi, layanan peminatan, bimbingan klasikal, konseling individu/kelompok, hingga career day [2].

Peserta didik kelas IX harus sudah dapat menentukan pilihan sekolah lanjutan, karena setelah lulus SMP mereka harus sudah dapat menentukan jurusan yang akan diambilnya. Maka informasi kelajutan studi diberikan pada peserta didik kelas VIII. Selama ini informasi kelanjutan studi bagi siswa SMP kelas VIII menggunakan metode ceramah, dalam layanan bimbingan klasikal dan bimbingan kelompok oleh guru BK. Efektivitas layanan ini ditunjang oleh media bantu baik media audio, media visual, media audio visual, hingga yang terintegrasi dengan internet.

Strategi bimbingan dan konseling komprehensif dalam perencanaan karier melalui implementasi empat komponen layanan. Layanan dasar dapat berupa bimbingan klasikal, bimbingan kelompok, dengan materi mengenal jenis keterampilan yang sesuai untukku, mengenal diri sendiri, dengan menggunakan media macro emotion card, dan pop up. Bimbingan kelompok dengan mengenal jenis pekerjaan yang cocok untuk pria dan wanita, dan tips menentukan studi lanjut dengan media flipchat. Layanan responsif untuk membantu untuk membantu siswa yang mengalami kesulitan atau hamabatan dalam proses merencanakan karier. Layanan peminatan dan perencanaan individual, strategi layanan perencanaan individual dan peminatan berupa layanan peminatan dalam format individu maupun kelompok untuk membantu siswa dalam pemahaman terkait diri, 
menemukan minat dan keterampilan diri, memahami program PAKET studi di SMA dan SMK, sehingga siswa dapat menentukan terkait studi lanjut [3].

Hamidjojo dan Latuheru (dalam [4]) mengemukakan bahwa media sebagai bentuk perantara yang digunakan oleh manusia untuk menyampaikan atau menyebar ide, gagasan dan pendapat sehingga dapat sampai pada penerima yang dituju. Media sendiri banyak dipakai dalam berbagai bidang kehidupan manusia terutama dalam proses pembelajaran. Dalam proses menyampaikan informasi kepada siswa, guru BK dapat menggunakan media sebagai alat bantu pembelajaran, baik berupa buku, poster, slide presentasi, hingga video. Media pembelajaran adalah suatu alat untuk mempertinggi proses interaksi guru dengan siswa dan interaksi siswa dengan lingkungan [5]. Menurut Gagne (dalam [6]) media pembelajaran diklasifikasikan menjadi tujuh kelompok yang dikaitkan dengan kemampuannya memenuhi fungsi hirarki belajar. Ketujuh kelompok ini yakni 1) benda untuk didemonstrasikan, 2) komunikasi lisan, 3) media cetak, 4) gambar diam, 5) gambar bergerak, 6) film bersuara, dan 7) mesin belajar.
Beragam penelitian pengembangan (R\&D) media bimbingan karier ini telah dilakukan sejak 2012-2018 oleh mahasiswa prodi bimbingan dan konseling di Indonesia. Penelitian ini mengulas tren media bimbingan karier pada jenjang SMP dan memberi evaluasi agar penelitian pengembangan media berikutnya dapat lebih inovatif dan efektif.

\section{METODE}

Metode yang digunakan dalam penelitian ini yakni analisis konten terhadap penelitian pengembangan media bimbingan karier khusus jenjang SMP pada tahun 20122018. Penliti menggunakan mesin pencari google scholar dengan kata kunci "media karier SMP". Analisis konten merupakan desain penelitian prosedural yang menghasilkan kesimpulan valid dari sebuah teks [7]. White \& Marsh [8] menegaskan bahwa dalam analisis konten, peneliti menggunakan analisis konstruk untuk memindahkan teks ke dalam jawaban pertanyaan penelitian.

\section{HASIL DAN PEMBAHASAN}

A. HASIL

Peneliti menemukan 27 penelitian pengembangan media yang terangkum pada tabel berikut:

TABEL I

PENELITIAN PENGEMBANGAN MEDIA BIMBINGAN KARIER PADA 2012-2018

\begin{tabular}{|c|c|c|c|}
\hline Tahun & Peneliti & $\begin{array}{l}\text { Media Bimbingan } \\
\text { Karier }\end{array}$ & Judul Penelitian \\
\hline 2012 & $\begin{array}{l}\text { Tiara, Wahyu } \\
\text { Subekti }\end{array}$ & $\begin{array}{l}\text { Modul perencanaan } \\
\text { karier model Career } \\
\text { Exploration Program } \\
\text { (CEP) }\end{array}$ & $\begin{array}{l}\text { Pengembangan Modul Perencanaan Karier Model Career Exploration Program (CEP) bagi Siswa } \\
\text { Sekolah Menengah Pertama }\end{array}$ \\
\hline 2012 & Fajrin O.N.S & Media internet & Pengembangan Media Layanan Informasi Karier Berbantuan Internet untuk Siswa SMP \\
\hline 2012 & Jannah N.I & Permainan monopoli & $\begin{array}{l}\text { Pengembangan Media Informasi Jenis-jenis Pekerjaan Berbentuk Permainan Monopoli dengan } \\
\text { Menggunakan Multimedia bagi Siswa SMP }\end{array}$ \\
\hline 2013 & Cahyono F.T & $\begin{array}{l}\text { Ensiklopedia karier } \\
\text { bergambar }\end{array}$ & Pengembangan Ensiklopedia Karier Bergambar Sebagai Media Informasi Karier Siswa SMP \\
\hline 2014 & Harsantik G.S & $\begin{array}{l}\text { Permainan tebak } \\
\text { gambar }\end{array}$ & $\begin{array}{l}\text { Pengembangan Media Game Tebak Gambar Untuk Membantu Eksplorasi Karier Siswa Kelas VII } \\
\text { SMP Negeri } 1 \text { Panggul }\end{array}$ \\
\hline 2014 & $\begin{array}{l}\text { Cahyawulan, W., } \\
\text { Hanim, W., \& } \\
\text { Herdi, H. }\end{array}$ & Komik & $\begin{array}{l}\text { Pengaruh Penggunaan Media Komik dalam Layanan Informasi Karier Untuk Meningkatkan } \\
\text { Kematangan Karier (Studi Kuasi Eksperimen Terhadap Peserta Didik Kelas VIII di SMP Labschool } \\
\text { Jakarta) }\end{array}$ \\
\hline 2014 & $\begin{array}{l}\text { Zamroni, E., } \\
\text { Sugiharto, D. Y. } \\
\text { P., \& Tadjri, I. }\end{array}$ & Multimedia interaktif & $\begin{array}{l}\text { Pengembangan Multimedia Interaktif Bimbingan Karier untuk Meningkatkan Keterampilan } \\
\text { Membuat keputusan Karier pada program Peminatan Siswa SMP }\end{array}$ \\
\hline 2014 & Patria R.I & $\begin{array}{l}\text { Modul berbantuan } \\
\text { computer }\end{array}$ & $\begin{array}{l}\text { Peningkatan Kemampuan Perencanaan Karier Melalui Modul Layanan Informasi Karier } \\
\text { Berbantuan Komputer pada Siswa Kelas VIII SMP Kristen } 2 \text { Salatiga }\end{array}$ \\
\hline 2014 & Setiawan M.F.A & Web server & $\begin{array}{l}\text { Pengembangan Materi Layanan Informasi Studi Lanjut Melalui Media Web Server Di Kelas VIII C } \\
\text { SMP Negeri } 1 \text { Prambon }\end{array}$ \\
\hline 2014 & $\begin{array}{l}\text { Pertiwi, D. A., \& } \\
\text { Sutarno, S. }\end{array}$ & Animasi Flash Player & $\begin{array}{l}\text { Pengembangan Media Flash Player@ untuk Meningkatkan Minat Melanjutkan Studi Peserta Didik } \\
\text { SMP }\end{array}$ \\
\hline 2015 & $\begin{array}{l}\text { Jainal, B., Rahim, } \\
\text { M., \& Puluhulawa, } \\
\text { M. }\end{array}$ & $\begin{array}{l}\text { Modul pemahaman } \\
\text { diri }\end{array}$ & $\begin{array}{l}\text { Pengembangan Modul Pemahaman Diri Sebagai Media Bimbingan Karier Siswa SMP Negeri } 1 \\
\text { Gorontalo }\end{array}$ \\
\hline 2015 & Dahlan N & Buku bergambar & $\begin{array}{l}\text { Efektivitas Informasi Karier dengan Media Buku Bergambar untuk Meningkatkan Pemahaman } \\
\text { Studi Lanjutan Siswa }\end{array}$ \\
\hline 2015 & Putriani D & Karpet berwarna & $\begin{array}{l}\text { Pengembangan Media Karpet Warna Untuk Membantu Perencanaan Karier Siswa Kelas VIII SMP } \\
\text { Negeri } 40 \text { Surabaya }\end{array}$ \\
\hline 2015 & Khoiriyah, N. L. & Flipbook & Pengembangan Panduan Penelusuran Peminatan di SMA bagi Siswa SMP dengan Media Flipbook \\
\hline 2016 & Priambodo, A. & Kartu karier & $\begin{array}{l}\text { Pengaruh Layanan Bimbingan Kelompok dengan Media Permainan Kartu Karier Terhadap Sikap } \\
\text { Pilihan Karier Siswa Kelas IX E Di SMP Negeri } 1 \text { Ungaran Tahun Ajaran 2015/2016 }\end{array}$ \\
\hline 2016 & $\begin{array}{l}\text { Oktaviana, M., \& } \\
\text { Christiana, E. }\end{array}$ & Kartu karier & $\begin{array}{l}\text { The Development Of Career Card Media For Career Planning 8th Gradestudent's In Smpn } 40 \\
\text { Surabaya. }\end{array}$ \\
\hline 2016 & Kamila. A. N & $\begin{array}{l}\text { Video animasi jendela } \\
\text { karier berbasis flash }\end{array}$ & $\begin{array}{l}\text { Pengembangan Media Video Animasi Jendela Karier Berbasis Flash Player Dalam Layanan } \\
\text { Informasi Perencanaan Karier di Sekolah Menengah Pertama }\end{array}$ \\
\hline
\end{tabular}




\begin{tabular}{|c|c|c|c|}
\hline & & player & \\
\hline 2016 & Fajirini & Monopoli karier & $\begin{array}{l}\text { Pengembangan Media Simulasi Monopoli Karier sebagai Alat Bantu Perencanaan Karier Siswa } \\
\text { SMP Negeri } 2 \text { Malang }\end{array}$ \\
\hline 2016 & Eliyanti F & $\begin{array}{l}\text { Software pemilihan } \\
\text { karier }\end{array}$ & $\begin{array}{l}\text { Pengembangan Software Pemilihan Karier Dengan Tipologi Holland untuk Sekolah Menengah } \\
\text { Pertama (Smp) Di SMP Negeri } 4 \text { Lamongan }\end{array}$ \\
\hline 2016 & Aprilia O.C & E-book & Pengembangan E-Book Informasi Karier untuk Siswa SMPN 2 Malang \\
\hline 2017 & $\begin{array}{l}\text { Yuwono, S. D., \& } \\
\text { Aidah, R }\end{array}$ & $\begin{array}{l}\text { Media pembelajaran } \\
\text { karier "Roe" berbasis } \\
\text { permainan }\end{array}$ & $\begin{array}{l}\text { Pengembangan Media Pembelajaran Karier "Roe" Berbasis Permainan sebagai Upaya Peningkatan } \\
\text { Wawasan }\end{array}$ \\
\hline 2017 & $\begin{array}{l}\text { Hidayat, R. E., } \\
\text { Suhendri, S., \& } \\
\text { Ajie, G. R. }\end{array}$ & Film & $\begin{array}{l}\text { Pengaruh Layanan Penempatan dan Penyaluran Melalui Media Film Terhadap Pemilihan Karier } \\
\text { Siswa Kelas VIII SMP Negeri } 1 \text { Pecangaan }\end{array}$ \\
\hline 2017 & $\begin{array}{l}\text { Muttaqin, R., } \\
\text { Wagimin, W., \& } \\
\text { Tadjri, I. }\end{array}$ & $\begin{array}{l}\text { Video interaktif dan } \\
\text { Live modelling }\end{array}$ & $\begin{array}{l}\text { Keefektifan Layanan Informasi Karier Berbantuan Video Interaktif dan Live Modeling untuk } \\
\text { Meningkatkan Pemahaman Karier Siswa SMP }\end{array}$ \\
\hline 2017 & $\begin{array}{l}\text { Kartika Saridewi, } \\
\text { N. N }\end{array}$ & Pion & Pengembangan Media Pion Perencanaan Karier Pada Siswa Kelas IX SMP Negeri 1 Besuki \\
\hline 2017 & Khoiroh, H & $\begin{array}{l}\text { Software pemilihan } \\
\text { jurusan }\end{array}$ & $\begin{array}{l}\text { Pengembangan Media Software Pemilihan Jurusan di SMA untuk Siswa Kelas VIII SMP Negeri } 1 \\
\text { Cerme }\end{array}$ \\
\hline 2017 & $\begin{array}{l}\text { Nurbaity, N., } \\
\text { Rizki, Y., Nadia, } \\
\text { N., Tawakal, I., \& } \\
\text { Rizky, M }\end{array}$ & Dumatari & Pengembangan Dumatari Sebagai Media Bimbingan Karier \\
\hline 2018 & $\begin{array}{l}\text { Arviani, S., \& } \\
\text { Setiawati, D }\end{array}$ & Wayang profesi & $\begin{array}{l}\text { Pemanfaatan Wayang Profesi dalam Bimbingan Klasikal untuk Meningkatkan Wawasan dan } \\
\text { Kesiapan Karier Kelas Olahraga (VII-A) di SMPN } 3 \text { Gresik }\end{array}$ \\
\hline 2018 & $\begin{array}{l}\text { Fandini, S. H., \& } \\
\text { Purwoko, B. }\end{array}$ & Adobe Flash & $\begin{array}{l}\text { Pengembangan Adobe Flash sebagai Media Layanan Informasi Peminatan Studi Lanjut SMA dan } \\
\text { Sederajat Untuk Siswa Kelas IX SMPN } 5 \text { Sidoarjo }\end{array}$ \\
\hline 2018 & Zakaria A.F & $\begin{array}{l}\text { Boardgame } \\
\text { Melankolis }\end{array}$ & $\begin{array}{l}\text { Media Layanan Informasi Karier Sekolah Lanjutan Bagi Siswa (Melankolis) untuk Meningkatkan } \\
\text { Pemahaman Siswa dalam Memilih Studi Lanjut Setelah SMP }\end{array}$ \\
\hline 2018 & $\begin{array}{l}\text { Zahrotul Badiah, } \\
\text { R. I. M. A., \& } \\
\text { Muis, T }\end{array}$ & $\begin{array}{l}\text { Aplikasi Model Cita- } \\
\text { cita Holland }\end{array}$ & $\begin{array}{l}\text { Pengembangan Aplikasi Cita-Cita Model Holland Untuk Siswa Berkebutuhan Khusus di SMP } \\
\text { Negeri } 13 \text { Surabaya }\end{array}$ \\
\hline 2018 & $\begin{array}{l}\text { Rofaul Alu Arif \& } \\
\text { Dibyo Wiyono } \\
\text { Bambang } \\
\end{array}$ & $\begin{array}{l}\text { Modul pemilihan } \\
\text { karier }\end{array}$ & Pengembangan Modul Pemilihan Karier Untuk Siswa Kelas IX SMPN 3 Babat Lamongan \\
\hline 2018 & $\begin{array}{l}\text { Murdiyanto, A., } \\
\text { Purwanta, E., \& } \\
\text { Kamaruddin, K. }\end{array}$ & $\mathrm{B} \log$ & $\begin{array}{l}\text { Pengembangan Layanan Informasi Karier Berbasis Media Blog untuk Meningkatkan Eksplorasi } \\
\text { Karier Siswa Di SMP Kota Magelang }\end{array}$ \\
\hline 2018 & $\begin{array}{l}\text { Zafifatun Nisa Evi } \\
\text { \& Warsito } \\
\text { Wiryosutomo } \\
\text { Hadi }\end{array}$ & $\begin{array}{l}\text { Aplikasi Cognitive } \\
\text { Information } \\
\text { Processing (CIP) }\end{array}$ & $\begin{array}{l}\text { Pengembangan Aplikasi Karier Model Cognitive Information Processing (CIP) untuk Perencanaan } \\
\text { Studi Lanjut Siswa Kelas IX SMPNegeri } 1 \text { Panceng Gresik }\end{array}$ \\
\hline 2018 & $\begin{array}{l}\text { Sulistya, H., \& } \\
\text { Bagus, O. T. }\end{array}$ & $\begin{array}{l}\text { Blog inventori } \\
\text { kepribadian }\end{array}$ & $\begin{array}{l}\text { Pengembangan Inventori Kepribadian Kecenderungan Karier RIASEC Berbasis Blog Untuk Siswa } \\
\text { SMP }\end{array}$ \\
\hline
\end{tabular}

\section{B. PEMBAHASAN}

Berdasarkan tabel di atas, tren penelitian pengembangan media dimulai pada tahun 2012. Peneliti tidak menemukan penelitian pengembangan media bimbingan karier sebelum tahun 2012. Secara umum tren penelitian ini meningkat positif dari tahun ke tahun. Jumlah penelitian terbanyak yakni di tahun 2018. Ini mengindikasikan adanya peningkatan minat dan kesadaran akan desain penelitian dan pengembangan $(R \& D)$ khususnya media bimbingan karier.

Selain kuantitas, jenis media yang dibuat pun beragam dan semakin inovatif. Berdasarkan kategori media pembelajaran Gagne (dalam Daryanto [6]), kategori media benda yang didemonstrasikan berjumlah 10 penelitian yang dibuat dalam bentuk media permainan baik kartu karier, monopoli karier maupun wayang profesi. Kategori media lisan tidak ada. Kategori media cetak berjumlah 7 penelitian yang dibuat dalam bentuk modul perencanaan, modul pelatihan dan buku saku. Kategori media gambar diam berjumlah 2 penelitian yang dibuat dalam bentuk media komik dan buku bergambar. Kategori media gambar bergerak berjumlah 4 media yang dibuat dalam bentuk animasi. Kategori film bersuara hanya berjumlah 1 penelitian yakni film. Kategori terakhir yakni media dengan teknologi internet berjumlah 11 penelitian yang dibuat dalam bentuk software, blog, dan aplikasi. Media yang terintegrasi dengan komputer/internet paling banyak dikembangkan karena menyesuaikan perilaku remaja saat ini yang gadget addict.

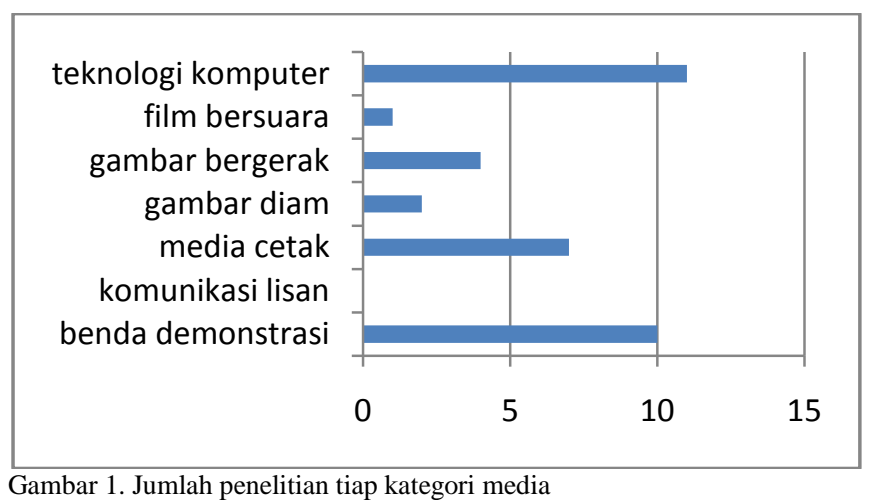


Peneliti memberi evaluasi pada setiap penelitian pengembangan media bimbingan karier di atas yakni pada aspek ketercapaian kompetensi. Peneliti memandang perlu menetapkan kompetensi karier yang ingin ditingkatkan sebagai dasar pengembangan media tersebut. Namun Indonesia belum memiliki acuan kompetensi karier yang rinci baik untuk jenjang SD, SMP, SMA maupun perguruan tinggi. Hal ini berbeda dengan di Amerika Serikat yang memiliki dua acuan utama dalam kompetensi karier, yakni ASCA Standard an NOICC Middle School Competencies. Sebagai contoh, NOICC Middle School Competencies menuliskan 4 kompetensi karier utama dan 23 subkompetensi. Setiap subkompetensi ini bisa ditingkatkan dengan sebuah media sehingga akan ada 23 media dengan fokus subkompetensi yang berbeda pula.

\section{KESIMPULAN}

Tren penelitian pengembangan media bimbingan karier untuk jenjang SMP di Indonesia mengalami peningkatan baik secara kuantitas maupun variasi jenis medianya. Peneliti selanjutnya diharapkan lebih memperhatikan aspek ketercapaian kompetensi karier agar media yang dikembangkan lebih terarah.

\section{DAFTAR PUSTAKA}

[1] Savickas, M. L. (2012). Life Design: A Paradigm For Career Intervention In The 21st Century. Journal of Counseling \& Development, 90(1), 13-19.

[2] Peraturan Menteri Pendidikan dan Kebudayaan RI Nomor 111 Tahun 2014 tentang Bimbingan dan Konseling Pada Pendidikan Dasar dan Pendidikan Menengah.

[3] Winkel, W. S., \& Hastuti. (2006). Bimbingan dan Konseling di Institut Pendidikan. Yogyakarta: Media Abadi.

[4] Arsyad, A. (2011). Media Pembelajaran. Yogyakarta: Rajawali Press.

[5] Rusman., Kurniawan, D., Riyana, C. (2015). Pembelajaran Berbasis Teknologi Informasi dan Komunikasi: Mengembangkan Profesionalitas Guru. Jakarta: Rajawali Pers.

[6] Daryanto. (2013). Media pembelajaran: Perannya sangat Penting dalam Mencapai Tujuan Pembelajaran. Yogyakarta: Gava Media.

[7] Weber, R. P. (1990). Basic Content Analysis (2 $2^{\text {nd }}$ ed.). Newbury Park, California: SAGE

[8] White, M. D., \& Marsh, E. E. (2006). Content Analysis: A flexible Methodology. Library Trends, 55(1), 22-45. 